\title{
Fiscal Transparency and Public Service Quality Association: Evidence from 12 Coastal Provinces and Cities of China
}

\author{
Qiuxia Yang
}

check for

updates

Citation: Yang, Qiuxia. 2021. Fiscal Transparency and Public Service Quality Association: Evidence from 12 Coastal Provinces and Cities of China. Journal of Risk and Financial Management 14: 13.

https: / / doi.org/10.3390/jrfm1401 0013

Received: 26 November 2020 Accepted: 24 December 2020 Published: 30 December 2020

Publisher's Note: MDPI stays neutral with regard to jurisdictional clai$\mathrm{ms}$ in published maps and institutional affiliations.

Copyright: () 2020 by the author. Licensee MDPI, Basel, Switzerland. This article is an open access article distributed under the terms and conditions of the Creative Commons Attribution (CC BY) license (https:// creativecommons.org/licenses/by/ $4.0 /)$.
School of Public Policy, Xiamen University, Xiamen 361005, China; yangqx1987@gmail.com

\begin{abstract}
This paper presents an evaluation index system of public service quality, which contains 35 indexes from the dimensions of the output and effect. Based on data from 2010 to 2017 in 12 coastal provinces and cities of China, this paper assesses public service quality by using the methods of entropy weight order preference similarity to the ideal solution (TOPSIS) and analyzes the effect of fiscal transparency on public service quality. The results show that the public service quality in the 12 coastal provinces and cities of China studied is relatively high, and fiscal transparency has a positive effect on public service quality. This analysis showed that an increase of $1 \%$ in fiscal transparency would lead to an increase of $0.0323 \%$ in the quality of public services. Fiscal transparency contributes to the quality of public services by improving the scale of investment and the efficiency of public services expenditure; this is because fiscal transparency can increase the expenditure on public welfare services and curb official corruption. Furthermore, the proposed evaluation index can enable government administrators to take the necessary steps on the appropriate dimensions to improve public service quality. This study can provide some guidelines for other countries, especially to improve public service quality by increasing fiscal transparency.
\end{abstract}

Keywords: fiscal transparency; public policy; public service quality; TOPSIS

\section{Introduction}

With the enhancement of living styles in China, the citizens are no longer solely satisfied with material needs only; they have begun to expect higher quality and more diversified public services. The Chinese government always pays great importance to the provision of public services as the starting point and main determinant of people's satisfaction. However, due to several levels of economic and social development of various regions in China, there are significant imbalances in the provision of public services in different regions, such as education, medical care, social security, culture, infrastructure, and environmental protection (Xin and Chen 2019). Currently, the Chinese government has continuously taken measures to improve public service quality through institutionalization to meet people's growing and diversified needs for public service, in which fiscal transparency plays an important role.

Fiscal transparency, as a type of system information on fiscal revenue and expenditure, can provide timely, complete, and reliable information on government fiscal activities so that the public can understand the government's activities and make relevant evaluations and decisions (Liu 2007). Currently, fiscal transparency is significantly used as a useful matrix for developing public service quality (Bauhr and Carlitz 2020). Transparency is publicly recommended as an essential condition for developing government quality, improving accountability, and minimizing the area of corruption (Bauhr and Grimes 2014; Islam 2006; Kosack and Fung 2014; De Renzio and Wehner 2017; Ríos et al. 2018; Stiglitz 2002; UNODC 2004). The authors of the article (Cicatiello et al. 2016) expressed a supportive view of fiscal transparency, as higher-level fiscal transparency plays a favorable role in developing a governance system. In papers (Wolfe 2003; Van Ryzin et al. 2004), the authors claimed that public satisfaction with and trust in local government was helpful for the 
political party to run its activities for a sustained period. Moreover, the fiscal transparency is conducive to the improvement of public service quality (Wolfe 2003). For policymakers all over the world, greater fiscal transparency is very important for self-evident reasons (Hu et al. 2020). Many countries, such as the UK (HM Treasury 1998), Spain (Esteller-Moré and Polo Otero 2012), and the USA (Alt et al. 2002) have made efforts to improve fiscal transparency (Best Practices for Budget Transparency n.d.; IMF 2007).

The previous research has provided enough theory and empirical evidence to understand the importance of fiscal transparency, but they rarely pay attention to the situation in China. Moreover, the demographic features of a region can directly impact fiscal transparency due to the way they shape public demand for government and local policies (Andreula and Chong 2016). In these circumstances, a fiscal transparency study, which is site-specific is more suitable for China, especially to assess the effectiveness of public services through fiscal transparency. These are some issues that deserve further study. How is public service quality in the coastal provinces and cities, which are the most developed regions in China? Has fiscal transparency that promotes the modern process of government governance contributed to the improvement of public service quality in these regions? What is the mechanism through which fiscal transparency affects public service quality? The answers to these questions can provide some reference for other countries, especially to improve the public service quality by increasing fiscal transparency.

The second section of this paper presents an index system for the evaluation of public service quality, which contains 35 indexes from various dimensions of output and effect. It measures public service quality by using the method of entropy weight TOPSIS, based on provincial panel data from 2010 to 2017 in 12 coastal provinces and cities of China. Currently, some researchers use stochastic dominance efficiency methodology as an alternative of TOPSIS for the specific case (Ahamdanech et al. 2020; Fidan Keçeci et al. 2016; Pinar et al. 2011, 2013, 2017, 2020; Valle et al. 2017). In the third section, this article analyzes the mechanism by which fiscal transparency affects public service quality, that is fiscal transparency can improve the scale and efficiency of public service expenditure by increasing public service welfare expenditure and curbing the occurrence of official corruption. In the fourth section, the panel data model is used to empirically analyze the effect and mechanism of fiscal transparency on the quality of public service and provides the empirical analysis. Finally, conclusions are drawn and suggestions for future work are given in Section 5 .

\section{Methodology: Evaluation of Public Service Quality}

\subsection{Evaluation Index System}

At present, the definition, classification, and scope of public service are still controversial in theory and practice (Alt and Lassen 2006; Heald 2003). According to different classification standards, scholars have sorted public services in different ways, such as by government functions, specific expenditure areas, content of public needs, etc. To comprehensively reflect the quality of public service, according to the standards in the "Thirteenth Five-Year Plan for Promoting the Equalization of Basic Public Services", issued by the "State Council of the People's Republic of China" and referred to in the literature, the scope of public services in this paper includes the areas that can ensure people's basic livelihood, such as basic education, medical services, infrastructure, social security, scientific and technological services, employment services, cultural services, social services, and environmental protection.

The evaluation of public service quality in literature is mainly based on the following four perspectives.

First, it is directly measured by the government's fiscal expenditure in a certain public service area. For example, per capita, fiscal expenditure on culture, education, science, and health is used to measure the quality of public services (Zulkofli et al. 2018; Pedrosa et al. 2020; Sun and Andrews 2020; Fan and Zhang 2013). This is the narrowest measurement 
method, which means a higher level of public services expenditure will inevitably lead to a higher quality of public services as so defined.

Second, the output of government fiscal expenditure can be used to assess the quality of public services, such as the total number of hospital beds per thousand people, the number of medical staff, and the teacher-student ratio to access the quality of public health and education services (Wu et al. 2014). This kind of index is at the intermediate stage between government fiscal expenditure and final output. It is a carrier of public services but is not the ultimate goal of fiscal expenditure.

Third, people's benefits from public services can be used to measure the quality of these services. For example, basic education is measured by the literacy rate and average years of education, and medical and health services are measured by average life expectancy. The ultimate goal of the government in providing public services is to improve the education level and health of the citizens by the intermediate output, thereby enhancing the welfare of the residents (Jia and Lu 2010).

Fourth, questionnaire surveys may be issued to measure the respondents' satisfaction with public services. Public service satisfaction reflects residents' subjective feelings about the quality of public service and can evaluate the quality of public services (Chen and Li 2010). However, due to the requirements for the accuracy and comprehensiveness of the questionnaire, and the influence on respondents of factors such as race, income, regional characteristics, and familiarity with public services (Kelly 2003), it is difficult for a satisfaction survey to truly reflect the actual situation of the respondents, and cannot objectively reflect the quality of public service.

Based on the above analysis, according to the principles of comprehensiveness, objectivity, representativeness, and accessibility, this article constructs an evaluation index system containing 35 indexes from dimensions of public service output and effect to comprehensively evaluate the public services quality, as mentioned in Table 1.

\subsection{Evaluation Method}

This paper used entropy weight TOPSIS to evaluate the quality of public service. This method was developed by Hwang and Yoon (Hwang and Yoon 1981) and further improvement was made by Hwang (Hwang et al. 1993). Hwang and Yoon proposed clustering, which is derived as an enhancement of the Wroclaw Taxonomy, which in turn is derived from the prior works of (Senetra and Szarek-Iwaniuk 2019; Czekanowski 1961). Many authors worldwide use the TOPSIS to evaluate, assess, and rank alternatives across diverse industries, such as Supply Chain Management and Logistics, Design Engineering and Manufacturing Systems, Business and Marketing Management, Health Safety and Environment Management, Human Resources Management, Energy Management, Chemical Engineering, Water Resources Management, and Other topics. (Behzadian et al. 2012; Lu and White 2014). The entropy weight TOPSIS method is a combination of the entropy method and TOPSIS method, in which the specific steps are as follows.

The first step is the positive processing of raw data.

Suppose there are $\mathrm{m}$ objects to be evaluated. Each evaluated object has $n$ evaluation indexes. $M=12$ refers to 12 provinces (cities and autonomous regions) in coastal provinces and cities of China; $n=35$ refers to 35 indexes that evaluate the quality of public service, constructing the following judgment matrix:

$$
X=\left(x_{i j}\right)_{m \times n}
$$

In Equation (1), $x_{i j}$ represents the value of a specific index, $i=1,2,3 \ldots, m$ and $j=1,2,3 \ldots, n$. To compare various indexes from different dimensions, this research adopts the extreme value standardization method to deal with each index in a positive direction. The indexes that reflect the public service quality can be sorted as positive and negative indexes. The greater the value of the positive indexes, the higher the public service quality: the greater the value of the negative indexes, the lower the public service quality. To ensure the same direction in these indexes, this research adopts different calculation 
methods for the positive and negative indexes. The standardization method of the positive indexes is as follows in Equation (2).

$$
x_{i j}^{\prime}=\frac{x_{i-} \min \left(x_{i j}\right)}{\max \left(x_{i j}\right)-\min \left(x_{i j}\right)}
$$

Table 1. Evaluation index system of public service quality.

\begin{tabular}{|c|c|c|c|c|}
\hline Target & Dimension & Item & Index & Effect \\
\hline \multirow{35}{*}{$\begin{array}{l}\text { Public service } \\
\text { quality }\end{array}$} & \multirow{18}{*}{ Output } & \multirow{2}{*}{ Basic education } & Teachers per 10,000 primary and secondary students & + \\
\hline & & & Schools per 10,000 primary and middle students & + \\
\hline & & \multirow{3}{*}{ Medical services } & Beds per 10,000 people & + \\
\hline & & & Medical and health institutions per 10,000 people & + \\
\hline & & & Medical and health personnel per 10,000 people & + \\
\hline & & \multirow{2}{*}{ Infrastructure } & Public transportation vehicles per 10,000 people & + \\
\hline & & & Public toilets per 10,000 people & + \\
\hline & & \multirow{2}{*}{ Social security } & Basic pension insurance fund expenditure per capita & + \\
\hline & & & Basic medical insurance fund expenditure per capita & + \\
\hline & & \multirow{2}{*}{$\begin{array}{l}\text { Scientific and } \\
\text { technological services }\end{array}$} & Scientific and technological personnel per 10,000 people & + \\
\hline & & & Patents granted per 10,000 people & + \\
\hline & & Employment services & Vocational technical training institutions per 10,000 people & + \\
\hline & & \multirow{2}{*}{ Cultural services } & Cultural institutions per 100,000 people & + \\
\hline & & & Publications per capita & + \\
\hline & & Social services & Social organization units per 10,000 people & + \\
\hline & & \multirow{3}{*}{ Environmental protection } & Wastewater discharge per capita & - \\
\hline & & & Exhaust gas emissions per capita & - \\
\hline & & & Solid waste per capita & - \\
\hline & \multirow{17}{*}{ Effect } & \multirow[b]{2}{*}{ Elementary education } & Average years of education & + \\
\hline & & & $\begin{array}{l}\text { The proportion of the illiterate population in the population } \\
\text { aged } 15 \text { and above }\end{array}$ & - \\
\hline & & \multirow{2}{*}{ Medical services } & Life expectancy & + \\
\hline & & & Maternal mortality rate $(1 / 100,000)$ & - \\
\hline & & \multirow{3}{*}{ Infrastructure } & Traffic density $\left(\mathrm{km} / \mathrm{km}^{2}\right)$ & + \\
\hline & & & Urban gas penetration rate (\%) & + \\
\hline & & & Internet access rate & + \\
\hline & & \multirow{2}{*}{ Social security } & Basic pension insurance coverage rate & + \\
\hline & & & Basic medical insurance coverage & + \\
\hline & & $\begin{array}{l}\text { Scientific and } \\
\text { technological services }\end{array}$ & Actual new product sales revenue per capita & + \\
\hline & & \multirow{2}{*}{ Employment services } & Urban registered unemployment rate & - \\
\hline & & & The ratio of successful public employment & + \\
\hline & & \multirow{3}{*}{ Cultural services } & The comprehensive population coverage rate of radio programs & + \\
\hline & & & The comprehensive population coverage rate of TV programs & + \\
\hline & & & Cultural activities visited per person & + \\
\hline & & Social services & Community service center (station) coverage rate & + \\
\hline & & Environmental protection & Harmless treatment rate of municipal solid waste & + \\
\hline
\end{tabular}

Note: " + " indicates that the index is positive and "- " indicates that the index is negative. A smaller value of the index indicates a higher quality of public services. 
The standardization method of the negative indexes is as follows in Equation (3).

$$
x_{i j}^{\prime}=1-\frac{x_{i-} \min \left(x_{i j}\right)}{\max \left(x_{i j}\right)-\min \left(x_{i j}\right)}=\frac{\max \left(x_{i j}\right)-x_{i j}}{\max \left(x_{i j}\right)-\min \left(x_{i j}\right)}
$$

In Equations (2) and (3), the terms $\max \left(x_{i j}\right)$ and $\min \left(x_{i j}\right)$ represent the maximum and minimum of a specific index, respectively. Thus, the standardized judgment matrix $X^{\prime}=$ $\left(x_{i j}^{\prime}\right)_{m \times n}$ can be established.

The second step is to calculate the entropy of the index.

According to the theory of information entropy, the entropy $e_{j}$ of the $j$-th index can be expressed as Equation (4).

$$
e_{j}=-k \sum_{i=1}^{m} y_{i j} \ln y_{i j}
$$

In Equation (4) the symbol can be calculated as $k=\frac{1}{\operatorname{lnm}}, y_{i j}=x_{i j}^{\prime} \backslash \sum_{i=1}^{m} x_{i j}^{\prime}$ and it is assumed that $\ln y_{i j}=0$, when $y_{i j}=0$.

The third step is to define the weight of the index.

If the diversity of the $j$ th index in each sample is smaller, the entropy of the index is larger. Conversely, if the diversity of the index in each sample is larger, the entropy of the index is smaller. Thus, the weight $w_{j}$ of the $j$ th index is defined as Equation (5).

$$
w_{j}=\left(1-e_{j}\right) \backslash \sum_{i=1}^{n}\left(1-e_{j}\right)
$$

In Equation (5) $w_{j} \in[0,1]$ and $\sum_{i=1}^{n} w_{j}=1$.

The fourth step is to form a norm matrix based on entropy weight.

Multiply the weight vector $w_{j}$ of each index by the standardized judgment matrix $X^{\prime}$ $=\left(x_{i j}^{\prime}\right)_{m \times n}$ to form a weighted standardized decision matrix as Equation (6).

$$
R=\left(r_{i j}\right)_{m \times n}=\left[w_{j} \cdot x_{i j}^{\prime}\right]_{m \times n}
$$

The fifth step is to determine the optimal solutions $\left(s_{j}^{+}\right)$as Equation (7) and worst solutions $\left(s_{j}^{-}\right)$as Equation (8).

$$
\begin{gathered}
s_{j}^{+}=\max \left(r_{1 j}, r_{2 j}, r_{i j} \ldots \ldots r_{m j}\right) j=1,2 \ldots \ldots n \\
s_{j}^{-}=\min \left(r_{1 j}, r_{2 j}, r_{i j} \ldots \ldots r_{m j}\right) j=1,2 \ldots \ldots n
\end{gathered}
$$

The sixth step is to compute the distance between each evaluated object and the optimal or worst solutions.

Using the Euclidean distance formula, calculate the distance $D_{i}^{+}$as Equation (9) and $D_{i}^{-}$as Equation (10) from the standardized vector of each evaluated index to the optimal solution and the worst solution.

$$
\begin{aligned}
D_{i}^{+} & =\sqrt{\sum_{j=1}^{n}\left(r_{i j}-s_{j}^{+}\right)^{2}} \quad i=1,2 \ldots \ldots m \\
D_{i}^{-} & =\sqrt{\sum_{j=1}^{n}\left(r_{i j}-s_{j}^{-}\right)^{2}} \quad i=1,2 \ldots \ldots m
\end{aligned}
$$


The seventh step is to calculate the degree of closeness of each evaluated object. Calculate the closeness degree $C_{i}^{*}$ of each evaluated object as Equation (11).

$$
C_{i}^{*}=\frac{D_{i}^{-}}{D_{i}^{-}+D_{i}^{+}} \quad i=1,2 \ldots \ldots m
$$

The value of $C_{i}^{*}$ is in-between 0 and 1 . The higher the value of $C_{i}^{*}$, the greater the quality of public service. When $C_{i}^{*}=1$, the quality of public services is the highest; when $C_{i}^{*}$ $=0$, the quality of public services is the lowest. According to the research results (Lei et al. 2016), the closeness degree can be divided into four grades to characterize the quality of public service, as shown in Table 2.

Table 2. The standards for judging the quality of public service.

\begin{tabular}{cc}
\hline Closeness Degree & Public Service Quality \\
\hline $0-0.30$ & Poor \\
\hline $0.30-0.60$ & Medium \\
\hline $0.60-0.80$ & Good \\
\hline $0.80-1.00$ & Excellent \\
\hline
\end{tabular}

\subsection{Evaluation Results}

Using data (2010-2017) from 12 coastal provinces and cities in China, the judgment matrix for every year can be established through the evaluation index system mentioned in Table 1. The entropy of each index was computed according to Equations (2)-(5). Similarly, the weight of every index was calculated by using Equations (6)-(10) to calculate the Euclidean distance $D_{i}^{+}$and $D_{i}^{-}$. Finally, the closeness degree $C_{i}^{*}$ was calculated using Equation (11).

The closeness degrees $C_{i}^{*}$ were sorted and shown in Table 3 . The public service quality in these coastal provinces and cities of China was relatively high. On average, from 2010 to 2017, except for Hainan, Hebei, and Guangxi, the closeness degree of public service quality was higher than 0.3. The closeness degree of Beijing was 0.6583 , which is greater than 0.6, indicating the public service quality was good, as shown in Table 2 . The closeness degree of the other 8 provinces and cities, including Shanghai, was between 0.3 and 0.6 , which suggests that the public service quality was of medium quality.

Table 3. The closeness degree of public service quality in 12 coastal provinces and cities of China.

\begin{tabular}{ccccccccccc}
\hline Coastal Provinces/Cities & $\mathbf{2 0 1 0}$ & $\mathbf{2 0 1 1}$ & $\mathbf{2 0 1 2}$ & $\mathbf{2 0 1 3}$ & $\mathbf{2 0 1 4}$ & $\mathbf{2 0 1 5}$ & $\mathbf{2 0 1 6}$ & $\mathbf{2 0 1 7}$ & Average \\
\hline Beijing & 0.6940 & 0.7091 & 0.6997 & 0.6349 & 0.6361 & 0.6277 & 0.6281 & 0.6369 & 0.6583 \\
\hline Shanghai & 0.6453 & 0.6103 & 0.5728 & 0.5188 & 0.5174 & 0.5323 & 0.5305 & 0.5275 & 0.5569 \\
\hline Zhejiang & 0.5537 & 0.5453 & 0.5638 & 0.5425 & 0.5324 & 0.5441 & 0.5603 & 0.5437 & 0.5482 \\
\hline Jiangsu & 0.4996 & 0.5312 & 0.5543 & 0.5008 & 0.4870 & 0.4938 & 0.4990 & 0.4726 & 0.5048 \\
\hline Tianjin & 0.5180 & 0.5013 & 0.4989 & 0.4743 & 0.4837 & 0.4856 & 0.4698 & 0.4600 & 0.4865 \\
\hline Guangdong & 0.4165 & 0.4110 & 0.4590 & 0.4162 & 0.4253 & 0.4220 & 0.4156 & 0.4241 & 0.4237 \\
\hline Liaoning & 0.3214 & 0.3121 & 0.3083 & 0.3069 & 0.3229 & 0.3189 & 0.3172 & 0.3258 & 0.3167 \\
\hline Fujian & 0.2921 & 0.3027 & 0.2963 & 0.3061 & 0.3766 & 0.3087 & 0.2881 & 0.2802 & 0.3064 \\
\hline Shandong & 0.3162 & 0.3106 & 0.3133 & 0.2960 & 0.3065 & 0.3026 & 0.2984 & 0.2853 & 0.3036 \\
\hline Hainan & 0.2138 & 0.2237 & 0.2285 & 0.2249 & 0.2234 & 0.2121 & 0.2790 & 0.2607 & 0.2333 \\
\hline Hebei & 0.2302 & 0.2266 & 0.2100 & 0.2532 & 0.2329 & 0.2435 & 0.2220 & 0.2302 & 0.2311 \\
\hline Guangxi & 0.1548 & 0.1548 & 0.1481 & 0.1656 & 0.1678 & 0.1748 & 0.1583 & 0.1716 & 0.1620 \\
\hline
\end{tabular}




\section{The Mechanism by Which Fiscal Transparency Affects Public Service Quality}

The institutional structure has an important effect on public service quality. Strengthening government accountability and providing key information to the public are important ways to improve governance ability and governance level (Haque and Neanidis 2009). The openness and transparency of fiscal information have increasingly become a key factor in improving the government's governance ability, which is the foundation for establishing a modern fiscal budget system. Moreover, it has an important effect on the structure and efficiency of fiscal expenditure. Several acceptable definitions of fiscal transparency have been provided, consisting of internationally reliable, systematic, and timely data on public revenues and expenses (Bastida and Benito 2007; Heald 2003; Kopits et al. 1998; Poterba and von Hagen 1999). Currently, public service provision in China is still dominated by government fiscal expenditure; as a result, fiscal transparency has an important effect on the quality of public service.

\subsection{Fiscal Transparency Affects the Scale of Government Fiscal Expenditure for Public Services}

A sufficient amount of public expenditure funds is the basis for improving the quality of public services. Fiscal transparency is conducive to the optimization of the structure of fiscal expenditures and promotes increased investment in public services. The transparency of fiscal information gives people information about government fiscal expenditure and effective supervision of government behavior, reducing the arbitrariness of fiscal expenditure and optimizing the structure of such expenditure. There is an important negative correlation between fiscal transparency and the administrative expenditure of local governments; the transparency and openness of public fiscal information can force local governments to reduce unnecessary administrative expenditure (Liu 2015). Fiscal transparency can also effectively reduce fiscal expenditure on ostentatious projects, increase the supply of public infrastructure and services (Bo et al. 2014), and direct fiscal expenditure more towards public health, education, and other public service areas. With the continuously deepening concept of building a service-oriented administration, people have expectations for higherquality public services (Ríos et al. 2016; Zeng 2014). Consequently, the Chinese government is more concerned about public services that relate to the public's vital interests, and is motivated to increase public service expenditure.

Concerning the above analysis, this article proposes the following hypothesis.

Hypothesis 1 (H1). Fiscal transparency is conducive to the improvement of public service quality by increasing the scale of public fiscal expenditure.

\subsection{Fiscal Transparency Affects the Efficiency of the Use of Government Fiscal Expenditure in Public Service}

Fiscal transparency is not only conducive to promoting the optimization of fiscal expenditure structure but is also conducive to enhancing the efficiency of the use of public service funds, thereby effectively improving fiscal transparency performance and increasing the quality of public service. However, excessive fiscal transparency does not necessarily equate to high efficiency; there is an inverted U-shaped relationship between fiscal transparency and efficiency. Before reaching the peak, fiscal transparency and efficiency are positively correlated. After this peak, excessive fiscal transparency will lead to overexposure, which in turn leads to the loss of efficiency (Heald 2003).

Although the total level of fiscal transparency is still low in China (Deng et al. 2018), it has been improving year by year through institutionalization. Fiscal transparency plays a vital role in improving the efficiency of public service funds by restraining official corruption. It can enable the public to more efficiently manage the use of fiscal funds, expose the government's wasteful, rent-seeking behaviors (associated with a high risk of government corruption), and form a strong constraint against government officials using the complexity and ambiguity of fiscal budgeting to engage in self-interested behavior. 
Thereby, fiscal transparency can effectively reduce government corruption, which is bound to reduce unnecessary waste of fiscal funds and promote their efficiency.

Concerning the above analysis, this article proposes the following hypothesis.

Hypothesis 2 (H2). Fiscal transparency can increase the quality of public service by influencing the efficient use of government fiscal expenditure in public service by reducing government corruption.

\section{Empirical Analysis}

\subsection{Model and Variables}

In China, the government has always been the main agency for supplying public service, which provides funds for public services through fiscal expenditure. Therefore, effective supervision for fiscal expenditure is directly related to public service quality, and fiscal transparency is an effective form of supervision. Concerning empirically analyzing the effect of fiscal transparency on the quality of public service, according to the characteristic structure of panel data and referring to the existing literature, this paper constructs the following panel data model. The panel data model can solve the problem of missing variables caused by individual heterogeneity and improve the validity of estimation by increasing sample information, but which can cause some problems, such as the error items of the same individual in different periods have autocorrelation.

$$
L P S_{i t}=\alpha_{i}+\beta_{i t} L X_{i t}+\gamma_{i t} L Y_{i t}+\mu_{i t}+\epsilon_{i t}
$$

In Equation (12), $i$ represents the province and $t$ represents time. The term $P S$ is an explained variable that represents the public service quality of the province $i$ on the period of $t$. The symbol $X$ is the core explanatory variable, which expresses fiscal transparency. The symbol $Y$ represents a series of control variables. Control variables include official corruption, government responsiveness, government administrative efficiency, fiscal capacity, urbanization, and urban-rural earnings gap. Furthermore, the symbol $\beta$ and $\gamma$ represent variable coefficients, $\alpha$ is the intercept term, $\mu$ is the individual effect, $\epsilon$ is the error term, and $L$ represents the logarithmic form of each variable. Fiscal transparency data was collected from the China Fiscal Transparency Evaluation Report issued by the Shanghai University of Finance and Economics. The report evaluated fiscal transparency by investigating the transparency of the governmental and departmental final budget in China.

Official corruption will amplify the discrepancy between the supply and need of public services, worsen input and outcome of public services, and weaken the effectiveness of public service resource allocation, thereby eroding the efficiency of public services and being unconducive to improving the public service quality. Official corruption is measured by the ratio of the number of corruption cases prosecuted by judicial authorities to the number of public officials. The data was collected from the Annual Work Report of the People Procuratorate of China and the China Labor Statistics Yearbook respectively.

The stronger the government's response to the needs of the citizen, the more accurate public services the government provides, and the higher the quality of public service. Government responsiveness is accessed by the proportion of welfare expenditure to total fiscal expenditure (Yin and Yang 2014). Welfare expenditure includes education, science, technology, culture, sports, media social security, employment, medical health, family planning, and housing security expenditure. All the data was collected from the Finance Yearbook of China.

The higher the administrative efficiency of the government, the more effective the use of fiscal funds and the more helpful in developing the quality of public service. The administrative efficiency of the government is measured by the per capita fiscal expenditure of the agency, which is a reverse index. The higher per capita fiscal expenditure of the agency, the lower the administrative efficiency. This is obtained by dividing the general public service expenditure by the number of public officials (Zhang et al. 2007; Zhang 2004). The data of general public service expenditure comes from the Finance Yearbook of 
each province, and the number of public officials comes from the China Labor Statistics Yearbook.

Fiscal capacity has a relatively important effect on the quality of public service. By the continuous improvement of fiscal capacity, the quality of public services will gradually increase (Lv and Wang 2008). Fiscal capacity is accessed by fiscal autonomy and per capita fiscal transfer payments. Fiscal autonomy is the ratio of fiscal net income to total expenditure (Chen 2010). The information comes from "Finance Yearbook of China" (University Tsinghua 2017).

Where the level of urbanization is higher, the government needs to provide more public facilities and public services, and a higher quality of public services. Urbanization is expressed by dividing the urban population of each province by the permanent population, and the data collected from the "China Statistical Yearbook". The reduction of the income gap among urban and rural areas makes the government's financial affordability for public services relatively light, which is favorable to the improvement of the quality of public service. The urban-rural income gap is accessed by the ratio of the per capita annual disposable income of urban inhabitants and rural inhabitants. The data comes from the "China Labor Statistics Yearbook" (Editorial Board 2018). The above-mentioned nominal variables eliminated the price changes based on the price level of 2010.

\subsection{Effect of Fiscal Transparency on Government Public Service Quality}

According to Table 4, Haussmann's test shows the difference of coefficients under different methods and the value of $p$ is less than the confidence level of $5 \%$. Therefore, this paper used a panel fixed effects model to empirically analyze the effect of fiscal transparency on public service quality.

Table 4. The result of Haussmann estimates.

\begin{tabular}{cccc}
\hline Test Summary & Chi-sq. Statistic & Chi-sq. d.f. & Prob. \\
\hline Cross-section random & 38.02 & 9 & 0.0000 \\
\hline
\end{tabular}

The estimation results are mentioned in Table 5. Model (1) reflects the predictable results of 12 coastal provinces and cities, and model (2) reflects the national estimate results. Fiscal transparency has no impact on improving public service quality nationally, except in coastal provinces and cities, which may be explained by the fact that the fiscal transparency level is higher there. This paper analyzed the estimated results of the model (1) in Table 5.

Fiscal transparency plays a helpful effect on the quality of public service in 12 coastal provinces and cities of China, where the analysis suggests that an increase of $1 \%$ in fiscal transparency would lead to an increase of $0.0323 \%$ in the quality of public services.

Official corruption is negatively correlated with the quality of public service, which means corruption is not helpful to the development of public service quality. The effect of the per capita fiscal expenditure of an agency on the quality of public services is significantly negative. This may be explained by the fact that excessive administrative expenditure has taken away a portion of the fiscal expenditure that should be used in the area of public services; a high level of per capita fiscal expenditure by an agency reflects that local government administrative efficiency is low.

The proportion of welfare expenditure on fiscal expenditure is positively correlated with public service quality. To increase welfare public service expenditure in fields such as education, science, technology, culture, sports, media, social security, employment, medical health, family planning, housing security, etc., will greatly increase the quality of public services.

The effect of per capita fiscal transfer payments on public service quality has a statistically significant positive effect, but an increase in fiscal autonomy has not effectively promoted an improvement in public service quality. This may be because the fiscal au- 
tonomy of most provinces is not high, and the assets for the supply of public services significantly rely on transfer payments from the central administration.

Table 5. The effect of fiscal transparency on the quality of public services in 12 coastal provinces and cities of China.

\begin{tabular}{|c|c|c|}
\hline Variable & Model (1) & Model (2) \\
\hline Fiscal transparency & $\begin{array}{l}0.0323 * \\
(0.0157)\end{array}$ & $\begin{array}{c}0.0150 \\
(0.0151)\end{array}$ \\
\hline Official corruption & $\begin{array}{c}-0.0457 \\
(0.0466)\end{array}$ & $\begin{array}{c}-0.0604 \text { * } \\
(0.0333)\end{array}$ \\
\hline Per capita fiscal & $-0.101^{* * *}$ & $-0.0629 * *$ \\
\hline expenditure of agency & $(0.0202)$ & $(0.0233)$ \\
\hline Proportion of welfare & 0.00201 & $0.107^{*}$ \\
\hline expenditure & $(0.0584)$ & $(0.0593)$ \\
\hline Fiscal autonomy & $\begin{array}{c}0.125 \\
(0.164)\end{array}$ & $\begin{array}{c}0.108 \\
(0.0758)\end{array}$ \\
\hline Per capita fiscal & $0.309 * *$ & $0.185^{* *}$ \\
\hline transfer payment & $(0.132)$ & $(0.0830)$ \\
\hline Urbanization rate & $\begin{array}{c}0.131 \\
(0.279) \\
\end{array}$ & $\begin{array}{c}0.867 * * * \\
(0.228)\end{array}$ \\
\hline Urban-rural income gap & $\begin{array}{c}-0.277^{* * *} \\
(0.108)\end{array}$ & $\begin{array}{c}-0.197^{* *} \\
(0.0899)\end{array}$ \\
\hline Constant & $\begin{array}{c}-3.240 * * \\
(1.195)\end{array}$ & $\begin{array}{c}-2.099 * * \\
(0.890)\end{array}$ \\
\hline Time & YES & YES \\
\hline
\end{tabular}

Urbanization is positively correlated with the quality of public service, which is consistent with the conclusion of (Xu and Zhao 2015), and indicates that urbanization is conducive to improving the quality of public services. The effect of the earnings gap between urban and rural areas on the quality of public services is significantly negative, which means it is not helpful to the improvement of the quality of public service. The reason may be that a large urban-rural income gap increases the burden of providing public services.

\subsection{Analysis of the Mechanism by Which Fiscal Transparency Affects the Quality of Public Service}

The previous analysis shows that fiscal transparency can effectively promote public service quality in the 12 coastal provinces and cities of China, which were studied, but further tests are warranted to demonstrate how it works.

Table 6 shows the test results of the mechanism by which fiscal transparency affects the quality of public service. Fiscal transparency is positively correlated with the proportion of welfare expenditure and negatively correlated with official corruption. This shows that fiscal transparency has, indeed, promoted the optimization of the fiscal expenditure structure, which increased the proportion of public service expenditure. Fiscal transparency is conducive to reducing the amount of official corruption and consequently improves the efficiency of public services. 
Table 6. Test of the mechanism of fiscal transparency affecting the quality of public services in 12 coastal provinces and cities of China.

\begin{tabular}{ccc}
\hline & $\mathbf{( 1 )}$ & $\mathbf{( 2 )}$ \\
\hline Variable & The Proportion of Welfare Expenditure & Official Corruption \\
\hline Fiscal transparency & $0.0853^{* * *}$ & $-0.157^{* *}$ \\
Official corruption & $(0.0260)$ & $(0.0684)$ \\
& 0.0673 & \\
Government & $(0.0566)$ & 0.0150 \\
Expenditure per capita & $0.0804^{* *}$ & $(0.0893)$ \\
Proportion of welfare & $(0.0297)$ & 0.257 \\
expenditure & & $(0.212)$ \\
Constant & $-0.772^{*}$ & $-6.111^{* * *}$ \\
& $(0.353)$ & $(0.405)$ \\
\hline
\end{tabular}

Note: (1) ${ }^{* * *}, * *$, and $*$ indicate the significance level of $1 \%, 5 \%$, and $10 \%$ respectively. (2) The standard errors of heteroscedasticity are shown in brackets.

\section{Conclusions}

This paper presented an evaluation index system of public service quality containing 35 indexes from dimensions of public service output and effect. It used the entropy weight TOPSIS method to measure the public service quality of 12 coastal provinces and cities of China from 2010 to 2017. The results show that the public service quality in these 12 coastal provinces and cities was relatively high. This paper analyzed the mechanism by which fiscal transparency affects public service quality. First, fiscal transparency could improve the scale of public service expenditure by increasing public service welfare expenditure. Second, fiscal transparency could improve the efficiency of public service expenditure by curbing the occurrence of official corruption. The panel data model was used to empirically analyze the effect and mechanism of fiscal transparency on the quality of public service. This study found that fiscal transparency had a positive effect on the quality of public services in 12 coastal provinces and cities of China. An increase of 1\% in fiscal transparency would lead to an increase of $0.0323 \%$ in the quality of public service. The proportion of welfare expenditure on fiscal expenditure was positively correlated with public service quality. An increase of $1 \%$ in the proportion of welfare expenditure would lead to an increase of $0.002 \%$ in the quality of public service. Official corruption was negatively correlated with the quality of public service. An increase of $1 \%$ in official corruption would lead to a decrease of $0.0457 \%$ in the quality of public service. Fiscal transparency was positively correlated with the proportion of welfare expenditure and negatively correlated with official corruption.

Given the role of fiscal transparency in promoting the quality of public services, many measures should be adopted to continuously improve fiscal transparency. First, establish the fiscal information disclosure standards, formulate operating procedures for fiscal information disclosure through legislation, clarify the content, subject, time, method, and principles of the disclosure, regulate the disclosure of government fiscal information, and disclose it to the public to the greatest extent. Second, incorporate fiscal transparency into the government budget performance appraisal system. Due to the lack of a unified disclosure standard, there are large differences in information disclosure for local governments. Local governments' fiscal transparency should be gradually included in the performance appraisal scope so that local governments have enough initiative to increase fiscal transparency. Third, adopt diversified fiscal information disclosure methods. In addition to requiring governments at all levels to disclose fiscal information on the Internet, the role of the media should be used to disclose fiscal information to people through newspapers, radio, and television. With the time of Internet big data comes, public accounts, Weibo and other well-known platforms should be used to disclose financial information. 
Funding: This research received no external funding.

Acknowledgments: The author would like to thank the reference materials authors.

Conflicts of Interest: The author declares no conflict of interest.

\section{References}

Ahamdanech, Ismael, Carmelo García-Pérez, and Mercedes Prieto-Alaiz. 2020. A Stochastic Dominance Approach to Evaluating Pro-Poor Growth-An Application to the Spanish Case. Sustainability 12: 1728. [CrossRef]

Alt, James E., David Dreyer Lassen, and David Skilling. 2002. Fiscal Transparency, Gubernatorial Approval, and the Scale of Government: Evidence from the States. State Politics \& Policy Quarterly 2: 230-50.

Alt, James E., and David Dreyer Lassen. 2006. Fiscal Transparency, Political Parties, and Debt in OECD Countries. European Economic Review 50: 1403-39. [CrossRef]

Andreula, Nicoló, and Alberto Chong. 2016. Do Good Institutions Improve Fiscal Transparency? Economics of Governance 7: 241-63. [CrossRef]

Bastida, Francisco, and Bernardino Benito. 2007. Central Government Budget Practices and Transparency: An International Comparison. Public Administration 85: 667-716. [CrossRef]

Bauhr, Monika, and Marcia Grimes. 2014. Indignation or Resignation: The Implications of Transparency for Societal Accountability. Governance 27: 291-320. [CrossRef]

Bauhr, Monika, and Ruth Carlitz. 2020. When Does Transparency Improve Public Services? Street-level Discretion, Information, and Targeting. Public Administration. [CrossRef]

Behzadian, Majid, S. Khanmohammadi Otaghsara, Morteza Yazdani, and Joshua Ignatius. 2012. A State-of the-Art Survey of TOPSIS Applications. Expert Systems with Applications 39: 13051-69. [CrossRef]

Best Practices for Budget Transparency. n.d. Development, Organisation for Economic Cooperation. Available online: http:// www.oecd.org/govern\%0Aance/budgeting/BestPracticesBudgetTransparency-complete\%0Awithcoverpage.pdf (accessed on 5 June 2020).

Bo, Yan, Yiyuan Ma, and Chunping Hu. 2014. Dose Fiscal Transparency Improve Government Performance?-A Case Study on B Town. Nanjing Journal of Social Sciences 4: 80-87.

Chen, Zhenming, and Deguo Li. 2010. Innovation Strategies for the Equalization and Effective Delivery of Basic Public Services-The Case of Fujian Province. Chinese Public Administration 1: 47-51.

Cicatiello, Lorenzo, Elina De Simone, and Giuseppe Lucio Gaeta. 2016. Political Determinants of Fiscal Transparency: A Panel Data Empirical Investigation. Economics of Governance 18: 315-36. [CrossRef]

Czekanowski. 1961. Race and Nationality in Europe. Race 3: 68-79. [CrossRef]

Chen, Shuo. 2010. Tax-Share Reform, Local Fiscal Autonomy and Public Goods Provision. China Economic Quarterly 4: 1427-46.

Deng, Shulian, Junping Zeng, Chunrong Zheng, and Ying Zhu. 2018. Assessment of Chinese Fiscal Transparency at Provincial Level in 2017. Journal of Shanghai University of Finance and Economics 20: 18-28.

Editorial Board. 2018. China Statistics Yearbook; Beijing: China Statistics Press. Available online: http://www.stats.gov.cn/tjsj/ndsj/20 18/indexeh.htm (accessed on 20 January 2020).

Fan, Ziying, and Jun Zhang. 2013. Transfer Payments, the Supply of Public Goods and the Expansion of Government Scale. World Economic Papers 2: 1-19.

Esteller-Moré, Alejandro, and Jose Polo Otero. 2012. Fiscal Transparency. Public Management Review 14: 1153-73. [CrossRef]

Fidan Keçeci, Neslihan, Viktor Kuzmenko, and Stan Uryasev. 2016. Portfolios Dominating Indices: Optimization with Second-Order Stochastic Dominance Constraints vs. Minimum and Mean Variance Portfolios. Journal of Risk and Financial Management 9: 11. [CrossRef]

Haque, M. Emranul, and Kyriakos C. Neanidis. 2009. Fiscal Transparency and Corruption. Centre for Growth \& Business Cycle Research Discussion Paper Series; Manchester: University of Manchester.

Heald, David. 2003. Fiscal Transparency: Concepts, Measurement and UK Practice. Public Administration 81: 723-59. [CrossRef]

HM Treasury. 1998. The Code for Fiscal Stability; London: HM Treasury.

$\mathrm{Hu}$, Qiuxian, Leibao Zhang, Wenyu Zhang, and Shuai Zhang. 2020. Empirical Study on the Evaluation Model of Public Satisfaction with Local Government Budget Transparency: A Case from China. SAGE Open 10: 2158244020924064. [CrossRef]

Hwang, Ching-Lai, Young-Jou Lai, and Ting-Yun Liu. 1993. A New Approach for Multiple Objective Decision Making. Computers E Operations Research 20: 889-99.

Hwang, Ching-Lai, and Kwangsun Yoon. 1981. Methods for Multiple Attribute Decision Making. In Multiple Attribute Decision Making. Berlin and Heidelberg: Springer, pp. 58-191.

IMF. 2007. Manual for Fiscal Transparency. Washington: IMF.

Islam, Roumeen. 2006. Does More Transparency Go along with Better Governance? Economics E Politics 18: 121-67.

Jia, Zhilian, and Hongyou Lu. 2010. Fiscal Decentralization and Effective Supply of Education and Public Goods of the People's Livelihood. The Journal of Quantitative E Technical Economics 6: 139-50.

Kelly, Janet M. 2003. Citizen Satisfaction and Administrative Performance Measures: Is There Really a Link? Urban Affairs Review 38: 855-66. [CrossRef] 
Kopits, George, Jon D. Craig, and George Kopits. 1998. Transparency in Government Operations. Washington: International Monetary Fund.

Kosack, Stephen, and Archon Fung. 2014. Does Transparency Improve Governance? Annual Review of Political Science 17: 65-87. [CrossRef]

Lei, Xunping, Qiu Robin, and Yong Liu. 2016. Evaluation of Regional Land Use Performance Based on Entropy TOPSIS Model and Diagnosis of Its Obstacle Factors. Transactions of the Chinese Society of Agricultural Engineering 3: 243-53.

Liu, Xiaoxia. 2007. On the Construction of the Government Financial Reporting System in China-From the Perspective of Fiscal Transparency. Contemporary Finance and Economics 2: 20-28.

Liu, Jia. 2015. The Effect of Local Government Fiscal Transparency on the Expenditure Structure-An Empirical Research Based on Provincial Panel Data in China. Journal of Zhongnan University of Economics and Law 1: 21-27.

Lu, Xun, and Halbert White. 2014. Robustness Checks and Robustness Tests in Applied Economics. Journal of Econometrics 178: 194-206. [CrossRef]

Lv, Wei, and Weitong Wang. 2008. Unbalanced Development, Public Services and Government Responsibility: An Analysis Based on Government Preference and Government Efficiency. Social Sciences in China 4: 52-64.

Pedrosa, Glauco Vitor, Ricardo A. D. Kosloski, Vitor G. de Menezes, Gabriela Y. Iwama, Wander C. M. P. da Silva, and Rejane M. da Costa Figueiredo. 2020. A Systematic Review of Indicators for Evaluating the Effectiveness of Digital Public Services. Information 11: 472. [CrossRef]

Pinar, Mehmet, Thanasis Stengos, and Nikolas Topaloglou. 2011. On the Construction of the Human Development Index: A Stochastic Dominance Approach. Paper presented at the Eurasia Business and Economic Society (EBES) Conference 2011, Istanbul, Turkey, June 1-3.

Pinar, Mehmet, Thanasis Stengos, and Nikolas Topaloglou. 2013. Measuring Human Development: A Stochastic Dominance Approach. Journal of Economic Growth 18: 69-108. [CrossRef]

Pinar, Mehmet, Thanasis Stengos, and Nikolas Topaloglou. 2017. Testing for the Implicit Weights of the Dimensions of the Human Development Index Using Stochastic Dominance. Economics Letters 161: 38-42. [CrossRef]

Pinar, Mehmet, Thanasis Stengos, and Nikolas Topaloglou. 2020. On the Construction of a Feasible Range of Multidimensional Poverty under Benchmark Weight Uncertainty. European Journal of Operational Research 281: 415-27. [CrossRef]

Poterba, James M., and Jürgen von Hagen. 1999. Fiscal Institutions and Fiscal Performance. Chicago: University of Chicago Press.

De Renzio, Paolo, and Joachim Wehner. 2017. The Impacts of Fiscal Openness. The World Bank Research Observer 13: 185-210. [CrossRef]

Ríos, Ana-María, Francisco Bastida, and Bernardino Benito. 2016. Budget Transparency and Legislative Budgetary Oversight: An International Approach. The American Review of Public Administration 46: 546-68. [CrossRef]

Ríos, Ana-María, María-Dolores Guillamón, Bernardino Benito, and Francisco Bastida. 2018. The Influence of Transparency Onbudget Forecast Deviations in Municipal Governments. Journal of Forecasting 37: 457-74. [CrossRef]

Van Ryzin, Gregg G., Douglas Muzzio, Stephen Immerwahr, Lisa Gulick, and Eve Martinez. 2004. Drivers and Consequences of Citizen Satisfaction: An Application of the American Customer Satisfaction Index Model to New York City. Public Administration Review 64: 331-41. [CrossRef]

Senetra, Adam, and Patrycja Szarek-Iwaniuk. 2019. The Implementation of the Wroclaw Taxonomic Method for the Identification and Evaluation of Problem Areas in the Warmia and Mazury Region in Poland-A Case Study. Socio-Economic Planning Sciences 67: 43-57. [CrossRef]

Stiglitz, Joseph. 2002. Transparency in Government. In The Right to Tell: The Role of Mass Media in Economic Development. Edited by Roumeen Islam. Washington: World Bank Institute, p. 33.

Sun, Shuo, and Rhys Andrews. 2020. The Determinants of Fiscal Transparency in Chinese City-Level Governments. Local Government Studies 46: 44-67. [CrossRef]

University Tsinghua. 2017. Fiscal Transparency Report of Chinese City-Level Governments. Beijing: Tsinghua University.

UNODC. 2004. United Nations Convention against Corruption, Priorities for the Provision of Technical Assistance. Sioux City: Global Programme against Corruption (GPAC).

Valle, Cristiano Arbex, Diana Roman, and Gautam Mitra. 2017. Novel Approaches for Portfolio Construction Using Second Order Stochastic Dominance. Computational Management Science 14: 257-80. [CrossRef]

Wolfe, Robert. 2003. Regulatory Transparency, Developing Countries and the WTO. World Trade Review 26: 157-82. [CrossRef]

$\mathrm{Wu}$, Lichao, Zichen Lin, and Yue Guan. 2014. Study on the Measurement and Influencing Factors of Equalization of Public Services in My Country. The Journal of Quantitative \& Technical Economics 8: 72-86.

Xin, Chongchong, and Zhiyong Chen. 2019. Distribution Dynamics, Regional Differences and Convergence of Basic Public Service Supply Level in China. The Journal of Quantitative E Technical Economics 8: 52-71.

$\mathrm{Xu}$, Yingzhi, and Yongping Zhao. 2015. New Urbanization, Local Government Fiscal Capacity and public service supply. New Urbanization, Local Government Fiscal Capacity and Public Service Supply 5: 4.

Yin, Heng, and Longjian Yang. 2014. Research into the Responsiveness of Local Government Finance to Resident Preferences. Social Sciences in China 5: 96-115.

Zeng, Jinghan. 2014. The Debate on Regime Legitimacy in China: Bridging the Wide Gulf between Western and Chinese Scholarship. Journal of Contemporary China 23: 612-35. [CrossRef] 
Zhang, Jun, Yuan Gao, Yong Fu, and Hong Zhang. 2007. Why Does China Enjoy so Much Better Physical Infrastructure? Economic Research Journal 3: 4-19.

Zhang, Gang. 2004. A Comparative Study on the Government Capacity of 16 Cities in the Yangtze River Delta. Management World 8: $18-27$.

Zulkofli, Adhwa Zulhilmi, Kauthar Nasiruddin, and Farah Raihana Ismail. 2018. Government expenditure on education and healthcare to the effect on GDP value: A case of Malaysia. International Journal of Accounting $\mathcal{E}$ Business Management 6: 95-112. [CrossRef] 